\title{
A Selected History of South African Inflation Perceptions: The Question Matters
}

\author{
Jannie Rossouw \\ Professor and Head of the School of Economics and Business Sciences \\ University of the Witwatersrand \\ Email: jannie.rossouw@wits.ac.za
}

Adél Bosch

Research Department, SA Reserve Bank

Email: adel.bosch@resbank.co.za

Vishnu Padayachee

Distinguished Professor, School of Economic and Business Sciences, University of the Witwatersrand Email: padayacheev2@ukzn.ac.za

\section{Doi:10.5901/mjss.2014.v5n23p126}

\section{Abstract}

This paper provides a selected historical overview of inflation perception surveys undertaken in South Africa between 2006 and 2010 with a view to assessing the nature of the link between inflation perceptions and inflation expectations in the latest 2012 survey. These surveys are undertaken to assess the perceptions of respondents on the degree in which historic inflation figures reflect perceptions of actual inflation, and to find some link to inflation expectations. All the earlier pilot studies on inflation perceptions and the representative samples undertaken between 2006 and 2010 (in total six pilot studies, three representative samples and one survey among central bank employees) failed to show any link between inflation perceptions and inflation expectations. These findings cast some doubt on the premise that a policy of inflation targeting anchors inflation expectations in the current rate of inflation and therefore in the announced inflation target policy rate. In response to the earlier survey results, the question on inflation perceptions was put in different ways to respondents in the most-recent (2012) inflation perception survey to retest the hypothesis that inflation perceptions and inflation expectations are linked. The findings of this survey are analysed in this paper. These findings show a possible link to inflation expectations, and will be the subject of further research. The conclusion on the assessment of inflation perceptions is that the question matters.

Keywords: Inflation credibility; inflation expectations; inflation perceptions; inflation surveys

\section{Introduction ${ }^{1}$}

This paper highlights the history of inflation perception surveys undertaken among individual respondents in South Africa, in the quest to link inflation perceptions and inflation expectations. Initially inflation perception surveys were reported as inflation credibility surveys, which are an accurate reflection of their objective, i.e. to assess the degree in which historic inflation figures are regarded as credible and accurate indications of price increases. However, in keeping with international literature where this research is called inflation perception surveys, a similar approach has been adopted in South Africa in reporting the 2012 survey results.

Survey results obtained from individual respondents are often referred to as household surveys. This is not an accurate reflection of such results (see for instance Rossouw and Fourie, 2009 on this matter), as the survey results reflect the view of one member of a household on a particular matter (inflation perceptions in this instance), rather than a consensus view of all members of such a household. This paper therefore uses the terminology individual inflation perceptions, rather than household inflation perceptions.

All the pilot studies on inflation perceptions and representative samples undertaken until 2010 (six pilot studies, three representative samples and one survey among central bank employees) did not show any link between inflation

\footnotetext{
${ }_{1}^{1}$ The views and opinions expressed in this paper do not necessarily reflect the views and opinions of the SA Reserve Bank or any of the
} Universities. 
perceptions and inflation expectations in South Africa. These findings cast some doubt on the premise that a policy of inflation targeting anchors inflation expectations in the current rate of inflation and therefore in the announced inflation target policy rate. It was therefore not possible to confirm or refute a hypothesis that inflation perceptions and inflation expectations are linked.

In response to the survey results (until 2010), the survey question on inflation perceptions was put in different ways to respondents in the most-recent (2012) inflation perception survey. The findings of this survey are analysed in this paper and the possible link to inflation expectations that can be the subject of further research, is also explored. This paper reports for the first time significant progress in the quest to find a link between inflation perceptions and inflation expectations of South African individuals.

The rest of this paper is structured as follows: By means of a literature review, section 2 provides a selected overview of the history of inflation surveys undertaken among individuals in South Africa. Section 3 reports the findings of the most-recent (2012) inflation perceptions survey undertaken among individual responses in South Africa. Section 4 compares inflation perceptions and inflation expectations. Section 5 highlights the conclusions from the research reported in this paper.

\section{Literature on the History of Inflation Surveys Undertaken in South Africa}

\subsection{Background}

Central banks in countries targeting inflation base their policies in part on a premise that inflation expectations are anchored in the current rate of inflation and the credibility of the policy of containing the future rate of inflation in the eyes of the public (see for instance Mishkin, 2004: 658 on this matter). Inflation expectations of individuals are surveyed periodically by means of opinion polls; an approach that South Africa has adopted in 1999 (Kershoff and Smit, 2002: 445). Although individual inflation expectation and perception surveys are the focus of this paper, expectations of other groups, e.g. business people, financial market analysts and trade unions are also surveyed by inflation-targeting countries.

Inflation has been contained successfully in countries where the authorities contained inflation expectations, although " ... a central bank ... does not have control over expectations of inflation" (Mishkin, 2004: 419). At best a central bank can follow consistent policies that enhance expectations of low future inflation. Expectations of future inflation are therefore based on current inflation rates and the public's perception of historic price increases. In a South African context Samuels stated that " ... once the market's expectations ... are broken, the problems of the transition to a non-inflationary era will become progressively easier. The eradication of inflationary expectations will not be easy" (1967: 355). This statement of Samuels was true in 1967 and remains true to this day.

\subsection{Inflation expectations surveys}

Inflation expectation surveys among South African individuals have been conducted on a quarterly basis since 1999 by the Bureau for Economic Research (BER) on behalf of the South African Reserve Bank (Kershoff, 2000: 1). The BER describes these surveys as household inflation expectations surveys, but as has been pointed out earlier, this paper describes these surveys as the inflation expectations of individuals. These surveys are undertaken by AC Nielsen on behalf of the BER, and survey results are obtained by means of personal interviews. The survey results of AC Nielson have consistently shown a very low percentage of individual responses indicating that they "don't know" what level of inflation to expect, as is highlighted in Table 1 below. In the $4^{\text {th }}$ quarter of 2012 the survey covered 2353 respondents (Bureau for Economic Research, 2012).

In this survey the BER put to respondents a statement and question that "(0)ver the past five years prices increased by on average 6,1 per cent per year. During 2010 prices increased by 4,3\%. By about how much do you expect prices in general to increase over the next 12 months? (sic)" (Bureau for Economic Research, 2012). The BER survey findings are summarised in Table 1.

Of particular importance in the context of the analysis in the rest of this paper is the fact that only 10,7 per cent of respondents have indicated that they "don't know" by how much prices in general will increase over the next 12 months, i.e. during 2012. Figure 1 suggests that compared to similar international inflation expectation surveys, South Africa has a relatively high percentage of 'don't knows' with only Greece having a higher percentage. It is worthy to note that the response options differ between surveys. In the EU survey response options are: [consumer prices will develop over the next 12 months] rise a lot; rise moderately; rise slightly; stay about the same; fall and don't know. The Reserve Bank of 
India's inflation expectations survey response option is provided in terms of inflation percentage brackets. For South Africa, the BER provides for the respondents to supply a numerical value of what they expect inflation to be over the next 12 months, as well as a don't know option.

The EU survey asks the same question and has the same response options for all EU countries. There are large variations in the share of "don't know" respondents when comparing the EU countries. The results for EU countries are presented in summarised format in Figure 1, although the results of a number of other countries, including South Africa, are included for comparative purposes.

Table 1: Details of survey results among individual respondents, $4^{\text {th }}$ Quarter 2011: Inflation expectations for 2012

\begin{tabular}{|c|c|c|c|c|c|c|c|c|c|}
\hline \multirow{3}{*}{$\begin{array}{l}\text { Survey quarter Expectations in } \\
\text { respect of }\end{array}$} & 2011Q2 & 2011Q3 & \multicolumn{7}{|c|}{ 2011Q4 } \\
\hline & 2011 & 2011 & \multicolumn{7}{|c|}{2011} \\
\hline & Average $^{1}$ & Average $^{1}$ & \multicolumn{7}{|c|}{ Average ${ }^{1}$ Std Dev $^{1}$ Median $^{1}$ Minimum Maximum $\%>25 \%{ }^{2} \%$ D/K 2} \\
\hline Total & 6.1 & 6.1 & 6.0 & 3.2 & 5 & 1 & 100 & 2.1 & 10.7 \\
\hline \multicolumn{10}{|c|}{ Per population group } \\
\hline Blacks & 5.8 & 5.9 & 5.9 & 3.2 & 5 & 1 & 100 & 2.1 & 10.8 \\
\hline Coloureds & 6.7 & 5.9 & 5.6 & 2.6 & 5 & 1 & 70 & 1.9 & 12.8 \\
\hline Indians & 6.6 & 6.6 & 6.1 & 3.0 & 5 & 1 & 100 & 2.6 & 5.0 \\
\hline Whites & 6.7 & 6.5 & 6.3 & 3.1 & 5 & 1 & 100 & 1.9 & 10.6 \\
\hline \multicolumn{10}{|c|}{ Per monthly household income } \\
\hline R8000+ & 6.3 & 6.2 & 5.9 & 2.9 & 5 & 1 & 100 & 2.4 & 9.8 \\
\hline R4000-R7999 & 6.3 & 6.1 & 6.2 & 3.4 & 5 & 1 & 100 & 2.4 & 7.3 \\
\hline R800-R3999 & 5.9 & 6.0 & 5.8 & 3.3 & 5 & 1 & 100 & 1.8 & 13.6 \\
\hline R1-R799 & 6.0 & 5.9 & 5.8 & 3.1 & 5 & 1 & 100 & 1.2 & 13.8 \\
\hline \multicolumn{10}{|c|}{ Per age group } \\
\hline $16-24$ & 5.9 & 6.1 & 5.7 & 3.2 & 5 & 1 & 70 & 2.7 & 7.5 \\
\hline $25-34$ & 6.0 & 6.1 & 6.0 & 3.1 & 5 & 1 & 100 & 1.4 & 10.3 \\
\hline $35-49$ & 6.3 & 6.0 & 6.0 & 3.0 & 5 & 1 & 100 & 1.8 & 11.3 \\
\hline $50+$ & 6.5 & 6.2 & 6.2 & 3.4 & 5 & 1 & 100 & 2.5 & 13.7 \\
\hline \multicolumn{10}{|c|}{ Per gender } \\
\hline Male & 6.1 & 6.1 & 6.0 & 3.2 & 5 & 1 & 100 & 1.9 & 9.1 \\
\hline Female & 6.2 & 6.1 & 5.9 & 3.2 & 5 & 1 & 100 & 2.3 & 12.6 \\
\hline \multicolumn{10}{|c|}{ Per community size } \\
\hline Metro & 6.2 & 6.0 & 5.9 & 3.3 & 5 & 1 & 100 & 2.7 & 11.7 \\
\hline Other urban & 6.1 & 6.1 & 6.0 & 3.0 & 5 & 1 & 100 & 1.1 & 9.3 \\
\hline
\end{tabular}

1 Excluding don't know and responses exceeding 25\%;

2 Percentage of responses exceeding $25 \%$ and don't know (D/K) respectively.

Source: Bureau for Economic Research, 2012

Figure 1: Percentage of don't know responses of individual respondents to a question requesting them to indicate by how much prices in general will increase (or developed) during the next 12 months

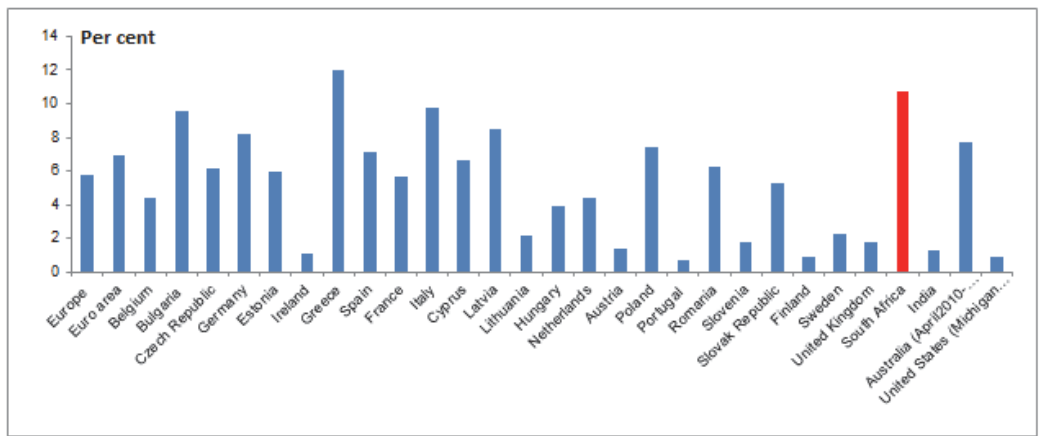

Source: European Commission: Joint Harmonised EU programme of Business and Consumer Surveys; Bureau for Economic Research (South Africa); Melbourne Institute survey of consumer inflation expectations (Australia); Michigan University: Survey of consumers (United States); Reserve Bank of India Inflation expectations survey (India). 


\subsection{Inflation perception surveys ${ }^{2}$}

The measurement of inflation perceptions among South African individuals commenced in 2003. A number of pilot studies $^{3}$ (six in total) were conducted to test various alternative questionnaires before the inflation perceptions of a representative sample of respondents were measured. The pilot studies have shown, inter alia, that respondents confuse the rate of inflation (i.e. price increases) with price levels ("things are expensive").

In the design of inflation perception surveys it was decided to provide the most recent official inflation figure at the time to respondents, as Kershoff and Smit state that "(t)he benefit of providing historical information is that all respondents have the same information available when completing the questionnaire ... (as) ... historic information provides respondents with a benchmark" (2002: 453). This approach was used in the pilot studies and in the representative surveys undertaken bi-ennially among South African individuals since 2006. The same approach is used by the Bureau for Economic Research in their quarterly inflation expectation surveys among individual respondents.

Insights gained from the six pilot studies on inflation perceptions informed the design of the first representative study on inflation perceptions among South African individuals. To ensure a representative sample of respondents, it was decided in 2006 to use Markinor (currently known as Ipsos) for fieldwork. This was the only suitable approach for a number of reasons (see Rossouw, 2006 for a complete discussion of these reasons):

- as only some 30 per cent of South Africans have residential landline telephones (National Gambling Board, 2005: 5), it was not possible to use telephonic surveys to obtain a representative sample;

- omnibus research is an accepted research practice used in many different fields of study to contain the cost of sampling (see for instance Camponovo, 2006; Kearney et al., 1999; or Lindenmann, 2001).

- Ipsos (or Markinor as it was known at the time) conducts biannual surveys among individual respondents to which additional questions can be added at a cost per question, as the infrastructure to conduct the research is already in place. The cost per respondent amounted to some R2,90 in 2006, while quotes obtained from alternative survey companies amounted to as much as R52,17 per respondent at the time. Cost was therefore an initial consideration to select the market research company, and service since 2006 has been at such a level that no consideration has since been given to the possible use of another market research company; and

- Ipsos covers at least 3500 respondents and the results are reported in terms of aspects such as employment status, gender, geographical location, income, etc., which are important parameters for this research.

The 2006-survey showed that 52,9 per cent of respondents indicated that they did not know whether the historic rate of inflation was an accurate indication of actual price increases in South Africa. Of the remaining respondents, 18,5 per cent said that the official historic inflation rate was a true reflection of actual average price increases, while 28,6 per cent believed that it is not a true reflection of actual average price increases.

One of the objectives of a survey is to obtain an estimate of the opinion of a population on a specific matter without interviewing every member of the population. Once survey results have been obtained, these can be used to estimate with different degrees of certainty (confidence intervals) the view of the general population represented by the sample on a specific matter. Confidence intervals provide an estimate of the possible size of any error in sampling data (see for instance Easton and McColl, [S.a.]).

The results of the survey were used to calculate a 90-per-cent confidence interval level in respect of the various responses of the respondents, with the value $z .05=1,645$ and a normal distribution implying that 0,9 (or 90 per cent) of the area below the curve is included between $z=-1,645$ and $z=1,645$ (see Rossouw, 2006 for a complete analysis of confidence intervals based on the first representative sample).

Number of observations in the sample (n) 3493

Number of successes

(x) 1644

Proportion

(p) $1644 \div 3493=0,471 ; \therefore q=0,529$

Standard error

(SE) $\sqrt{\frac{0,471 \times 0,529}{3493}}=0,0084$

Normal probability distribution

(z) 1,645 for a 90-per-cent confidence interval

The confidence interval at a level of 90 per cent is calculated as:

$[0,471-1,645(0,0084) \leq \Pi \leq[0,471+1,645(0,0084)]$

$0,4572 \leq \Pi \leq 0,4848$

There was a 90-per-cent probability in 2006 that between 51,5 per cent and 54,8 per cent of the actual population

2 This section draws, inter alia, on Rossouw et al, 2009; Rossouw et al, 2010; Rossouw et al, 2011 and Rossouw et al, 2013.

3 See for instance Struwig and Stead (2001) on the use of pilot studies in preparation for the sampling a representative population. 
"don't know" whether the historic rate of inflation was a true indication of actual price increases. Similarly, between 45,2 per cent and 48,5 per cent of the population had a view on the question whether the historic rate of inflation was a true reflection of actual price increases, irrespective of whether they accepted it as accurate or not. The confidence indicator shows that a large percentage of the population "don't know" whether the rate of inflation is an accurate indication of price increases.

The research was repeated in 2008 to re-assess the results of the survey undertaken in 2006. The 2008 survey showed broadly the same results as the 2006 survey, with the same percentages of respondents indicating that they accepted as accurate the rate of inflation as an indication of historic price increases (i.e. answered "yes"), respondents answering "no" and of respondents indicating that they "don't know" whether the historic rate of inflation accurately reflected price increases in the domestic economy. The limitation emanating from this research remained, namely that the survey results could not be compared to survey results of individuals on inflation expectations, owing to the larger percentage of "don't know" responses.

It was also decided in 2008 to undertake this research among employees of the South African Reserve Bank (see Rossouw et al, 2008 for a complete report on this research). This was done only once, as employees of the central bank reported even lower perceptions of the historic rate of inflation as an accurate indicator of historic price increases than the general South African population represented by the surveys. An even smaller percentage than in representative samples of the population answered "yes" to a question that they accept as accurate the historic rate of inflation as an indication of actual price increases. This was a result not expected from central bank employees, as these are the very people entrusted, among others, with the responsibility of conducting monetary policy to contain inflation. An analysis of possible reasons why central bank employees had low perceptions of their own success in containing inflation in 2008, is beyond the scope of this paper.

A different approach was followed in the third bi-ennial survey in 2010. Respondents who indicated that they did not accept as accurate the historic rate of inflation (i.e. answered "no"), were asked in a follow-up question to indicate their perception of the historic rate of inflation. This approach provided particular insights into views of respondents and therefore informed changes in respect of the way in which the survey question should be formulated in conducting inflation perception surveys.

\section{Survey Results of the 2012 Bi-Ennial Inflation Perceptions Survey}

The approach used in the bi-ennial survey undertaken in 2012 differed from the earlier approaches to obtain a better insight in to respondents' views of historic price changes. This objective was indeed achieved in the 2012 bi-ennial survey, as is explained in this section. These results and the basis that it provides for further research in confirming or refuting the hypothesis that inflation perceptions feed inflation expectations, have not been published before.

The questions used in the 2012 inflation perceptions survey were modeled as closely as possible on the question used in the individual inflation expectations surveys of the BER. It was decided to split the respondents in the Ipsos sample into two groups and to put slightly different questions to these two groups to:

- ensure compatibility with earlier survey results and see whether the high number of "don't know" responses persists; and

- compare the results obtained from these two subsamples to ascertain the most-suitable way forward for finding an answer to the hypothesis under consideration.

In view of the large number of respondents in the Ipsos survey (at least 3500 respondents), it was possible to make the required split, as each subsample still comprised a considerable number of respondents (at least 1750 in each instance). This sample comprised some 2000 individuals in metros and some 1500 non-metro inhabitants, with an equal gender split. A 25 per cent telephonic back check was made by Ipsos after the interviews to confirm that interviews had indeed been conducted. In practice the survey comprised 3563 respondents, rather than 3500 as planned originally. It is normally the case with large surveys that the actual respondents marginally exceed the planned number of respondents, should it be necessary to omit certain responses based on the back-check.

Ten pilot interviews were conducted by Ipsos on the questionnaire prior to the actual fieldwork to confirm its suitability for fieldwork sampling. This pilot was done, inter alia, to test interview length. The pilot went well and no issues occurred, implying that the fieldwork could proceed. The random sample technique used for the sampling ensures that each person in the South Africa adult population over the age of 15 has an equal probability of being chosen for interviews.

Respondents in both subsamples were provided with a statement, based on the approach used by the BER, namely "(o)ver the past five years prices increased by on average 6,8 per cent per year. Over the past 12 months prices 
increased by 5,5 per cent". The question differs from the question used by the BER, as the periods covered by the statements do not overlap.

The first subsample (1 776 respondents) was asked as a follow-up question "(b)y how much do you think prices in general increased during the past 12 months?", and were not provided up front with an opportunity to answer "yes", "no" or "don't know", although some respondents opted to answer "don't know" without any prompting. In this instance the responses differed considerably from the responses in the second subsample (1 787 respondents), where respondents were provided up front with these three optional answers with an opportunity to answer "yes", "no" or "don't know". The same pattern as with earlier bi-ennial surveys were reported, namely that more than 50 per cent of the respondents reported that they "don't know" whether the rate of inflation was a true reflection of average price increases. Respondents who answered "no", were asked a follow-up question on their inflation perceptions (see Figures 3 and 4).

Figure 2: Responses of individual respondents to a question requesting them to indicate by means of an actual number by how much prices in general increased during the past 12 months

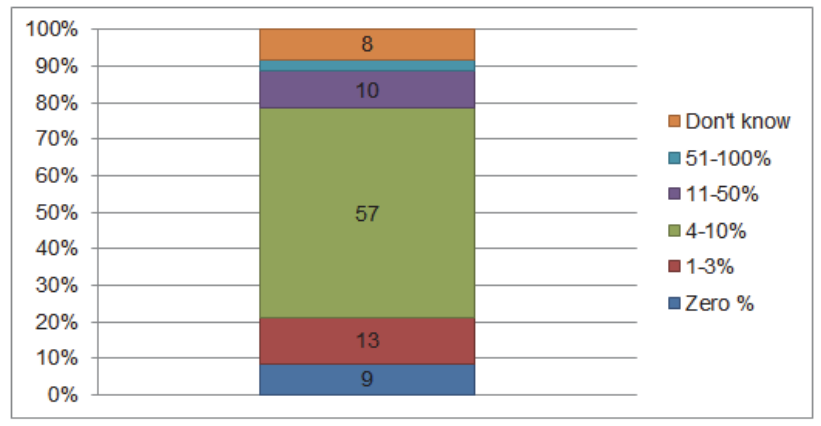

Source: Ipsos, 2012

The most marked and important difference is that 56 per cent of respondents opted for "don't know" when provided an option to choose between "yes", "no" and "don't know" as is shown below in respect of the second subsample, whereas only 8 per cent of respondents in the first opted for "don't know" when asked to provide a number for the historic inflation rate (see Figure 2). A similar trend was observed in responses obtained from the BER surveys, where 10,7 per cent of respondents answered "don't know" in the survey discussed above. By slightly altering the inflation perception question, the percentage of "don't know" responses was largely reduced. This shows that the question matters, i.e. the difference in the way in which the question is asked, influences the response obtained in the survey. This important finding is in itself significant and might have relevance outside the narrow field of inflation perception research. It shows that the wording of research questions has a bearing on the responses provided by respondents. Researchers should therefore test their questions carefully. The question can inform the response, not only in inflation perception surveys. For example, in many instances similar research on inflation expectations (see for example Bank of Japan (2013), Reserve Bank of India (2012); or Reserve Bank of New Zealand [S.a.]) do not provide for a "don't know" response at all.

Figure 3 summarises the responses to the follow-up question of the 333 respondents who answered "no" (i.e. they did not accept as accurate the rate of inflation as a true reflection of average price increases). These respondents were asked to then provide an indication of their perception of the historic rate of inflation.

Figure 3: Responses of individual respondents to a question whether the rate of inflation is a true reflection of average price increases

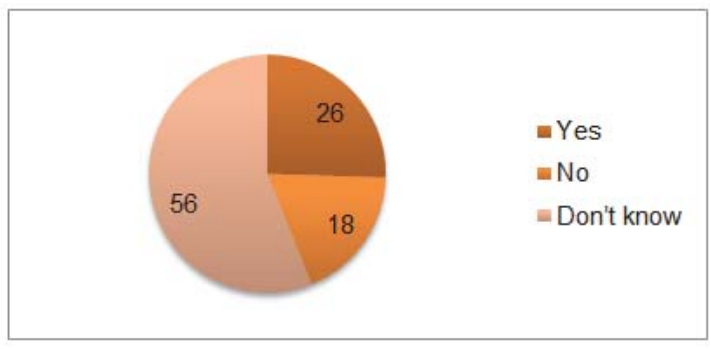

Source: Ipsos, 2012 
It is also noteworthy that the 333 respondents who were asked the follow-up question on their perception of inflation (i.e. those who answered "no"), gave responses aligned to the responses of the respondents who were asked to provide an actual figure for their inflation perceptions (see Figure 4). This matter is analysed in more detail in the next section.

Figure 4: Indication of perceptions of the historic rate of inflation

Source: Ipsos, 2012

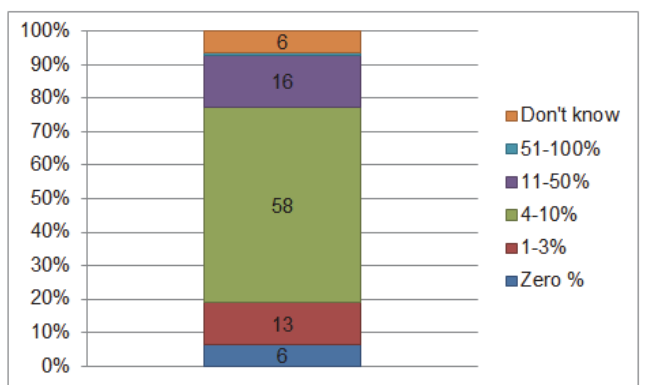

\section{Comparison of Inflation Perceptions and Inflation Expectations}

The most-recent 2012 inflation perception survey was split into two subsamples, as is explained above. The responses obtained in the first subsample, namely where respondents were asked to provide a perception of historic price increases, are most encouraging and provide a basis for comparison with the inflation expectation survey of the BER, also reported above.

The results to the question for respondents in the first subsample on the perception of historic price increases that was posed to the full sub-sample are presented in Table 2. These results were closest to the results from the BER survey, as respondents were not asked whether they thought that current price increases (as at June 2012) were a true reflection of average price increases.

Table 2: Descriptive statistics from the first sub-sample who were asked "what they believed price increases were over the past 12 months" (i.e. no credibility question)

\begin{tabular}{|c|c|c|c|c|c|c|c|}
\hline \multirow{2}{*}{$\begin{array}{l}\text { Question 1: Over the past } 12 \text { months } \\
\text { prices increased by } 5,5 \text { per cent. By how } \\
\text { much do you think prices in general } \\
\text { increased during the past } 12 \text { months }\end{array}$} & \multicolumn{7}{|c|}{2012} \\
\hline & Average $^{1}$ & Std Deviation ${ }^{1}$ & Median $^{1}$ & Minimum & Maximum & $\%>25 \% 2$ & $\begin{array}{l}\% \text { don't } \\
\text { knows }^{2}\end{array}$ \\
\hline Total & 6.4 & 4.1 & 6 & 0 & 90 & 5.5 & 8.3 \\
\hline \multicolumn{8}{|l|}{ Per population group } \\
\hline $\begin{array}{l}\text { White } \\
\text { Black } \\
\text { Indian } \\
\text { Coloured }\end{array}$ & $\begin{array}{l}7.8 \\
6.1 \\
8.9 \\
6.5\end{array}$ & $\begin{array}{l}4.9 \\
3.9 \\
6.9 \\
3.7\end{array}$ & $\begin{array}{l}7 \\
6 \\
8 \\
6\end{array}$ & $\begin{array}{l}0 \\
0 \\
0 \\
0\end{array}$ & $\begin{array}{l}80 \\
90 \\
90 \\
80\end{array}$ & $\begin{array}{c}7.0 \\
4.8 \\
19.3 \\
5.3\end{array}$ & $\begin{array}{c}5.0 \\
8.6 \\
7.2 \\
10.7\end{array}$ \\
\hline \multicolumn{8}{|l|}{ Per monthly household income } \\
\hline $\begin{array}{l}\text { R8000+ } \\
\text { R4000-R7999 } \\
\text { R800-R3999 } \\
\text { R1-R799 }\end{array}$ & $\begin{array}{l}7.0 \\
6.5 \\
5.9 \\
5.3\end{array}$ & $\begin{array}{l}4.3 \\
4.0 \\
4.0 \\
3.9\end{array}$ & $\begin{array}{l}7 \\
6 \\
6 \\
6\end{array}$ & $\begin{array}{l}0 \\
0 \\
0 \\
0\end{array}$ & $\begin{array}{l}80 \\
90 \\
90 \\
90\end{array}$ & $\begin{array}{l}7.5 \\
5.8 \\
6.9 \\
6.3\end{array}$ & $\begin{array}{l}2.1 \\
3.6 \\
9.6 \\
8.8\end{array}$ \\
\hline \multicolumn{8}{|l|}{ Per age group } \\
\hline $\begin{array}{l}15-24 \\
25-34 \\
35-49 \\
50+\end{array}$ & $\begin{array}{l}6.5 \\
6.7 \\
6.2 \\
6.0 \\
\end{array}$ & $\begin{array}{l}3.9 \\
3.9 \\
4.3 \\
4.2 \\
\end{array}$ & $\begin{array}{l}7 \\
6 \\
6 \\
6\end{array}$ & $\begin{array}{l}0 \\
0 \\
0 \\
0\end{array}$ & $\begin{array}{l}66 \\
90 \\
90 \\
90\end{array}$ & $\begin{array}{l}4.0 \\
6.6 \\
6.0 \\
5.3\end{array}$ & $\begin{array}{c}5.1 \\
8.4 \\
8.0 \\
11.9\end{array}$ \\
\hline \multicolumn{8}{|l|}{ Per gender } \\
\hline $\begin{array}{l}\text { Male } \\
\text { Female }\end{array}$ & $\begin{array}{l}6.4 \\
6.2\end{array}$ & $\begin{array}{l}4.0 \\
4.3\end{array}$ & $\begin{array}{l}6 \\
6\end{array}$ & $\begin{array}{l}0 \\
0\end{array}$ & $\begin{array}{l}90 \\
90\end{array}$ & $\begin{array}{l}4.5 \\
7.3\end{array}$ & $\begin{array}{l}8.5 \\
8.0\end{array}$ \\
\hline \multicolumn{8}{|l|}{ Per community size } \\
\hline $\begin{array}{l}\text { Metro } \\
\text { Non-metro }\end{array}$ & $\begin{array}{l}6.9 \\
6.1\end{array}$ & $\begin{array}{l}4.2 \\
4.1\end{array}$ & $\begin{array}{c}6.7 \\
6\end{array}$ & $\begin{array}{l}0 \\
0\end{array}$ & $\begin{array}{l}90 \\
90\end{array}$ & $\begin{array}{l}6.8 \\
4.7\end{array}$ & $\begin{array}{l}9.4 \\
7.7\end{array}$ \\
\hline
\end{tabular}

${ }^{1}$ Excluding don't knows and responses exceeding 25\%; 'Percentage of responses exceeding $25 \%$ and don't know respectively.

Sources: Ipsos, 2012 and authors' research 
The focus of this research is a comparison of the basic descriptive statistics between the results of the first sub-sample in the Ipsos survey and the results from the BER. For this purpose the BER inflation expectations recorded in 2011 for one year ahead, i.e. for 2012, is compared with the Ipsos results on inflation perceptions recorded at the end of 2012 for the preceding year, i.e. also for 2012. To restate: The BER survey asked respondents what their inflation expectations were for the next 12 months, while the Ipsos survey asked what the perceived inflation for the previous 12 months were. The fourth quarter 2011 BER survey is therefore compared to the 2012 Ipsos survey, as the Ipsos survey was conducted between 8 October and 19 November 2012.

Overall, the BER survey recorded an average expected rate of inflation of 6,0 per cent for 2012 in the fourth quarter of 2011, while the Ipsos survey showed a perception of an average rate of 6,4 per cent. The actual rate of inflation in 2012 was 5,6 per cent (Statistics SA, [S.a.]).

The standard deviation, however, was lower for the BER survey $(3,2)$ while for the Ipsos survey, the standard deviation was 4,1 per cent. The standard deviation gives an indication of average spread of the data. The BER had a median of 5 per cent and Ipsos had a median value of 6 per cent. Interestingly, the BER survey results has a minimum of 1 per cent and a maximum of 100 per cent, while the Ipsos survey results has a minimum of 0 per cent and maximum of 90 percent. Around 8,7 per cent of the Ipsos respondents (excluding don't knows) reported 0 per cent. The BER survey also had a lower share of respondents who had a value above 25 per cent. Overall the BER survey recorded a larger percentage of respondents who don't know what rate of inflation to expect than the percentage of respondents in the Ipsos survey who reported that they don't know what historic rate of inflation to perceive. This was also true in all of the demographic breakdowns.

The main findings from the breakdown by selected demographic criteria showed whites had higher inflation expectation for 2012; but when asked what they perceived historic inflation to be, Indians had a higher perceived rate. Compared to the other population groups surveyed by the BER, coloureds expected inflation to be the lowest; while from the Ipsos survey blacks had the lowest inflation perception. Interestingly, Indians also had a much larger share of respondents who reported a perception of inflation above 25 per cent, according to the Ipsos survey.

Different results can be observed when income groups are compared. In the Ipsos survey, respondents with household incomes exceeding R8 000 reported the highest perceived inflation rate, while in the BER survey, respondents with household incomes in the second highest income category (R4 000 - R7 999) had the highest inflation expectations. The lowest perceived/expected inflation rate was recorded for both surveys in the lowest two income categories. At the same time these two groups also had the highest percentage of respondents indicating that they "don't know" what rate of inflation to perceive and to expect. It seems therefore that respondents in these income groups have less pronounced inflation perceptions and expectations.

It is noteworthy that there are large differences between age groups. The Ipsos survey found that the youth (aged 15 to 34) had a higher perceived rate of inflation; while the BER found that the older generation (age 35-50+) had a higher level of inflation expectations.

Males expected the inflation rate for 2012 to be about 6,0 per cent; while when asked at the end of 2012 what they perceived inflation to have been, they reported 6,4 per cent. Females expected the inflation rate to be 5,9 per cent; while the their perceived inflation rate at the end of 2012 was 6,2 per cent. Respondents in non-metro areas expected inflation to be 6 per cent; while perceived inflation among this group of respondents at the end of the period was 6,1 per cent. Respondents in metro areas expected inflation of 5,9 per cent; while perceived inflation among this group of respondents was 6,9 per cent.

Overall expected inflation was much lower than perceived inflation. Acknowledging that there might be difficulty in the overlapping time (12 months forward; and 12 months historic); the results seems to suggest that forward looking inflation expectations is in general lower, and that respondents' overall perceived inflation ex post for the same period (after experiencing price increases) is higher. 
Table 3: Descriptive statistics from the second sub-sample who were asked "what they believed price increases were over the past 12 months" after a credibility question (yes, no or don't know)

\begin{tabular}{|c|c|c|c|c|c|c|c|}
\hline \multirow{2}{*}{$\begin{array}{l}\text { Question } 2 / 3 \text { : If respondents answered } \\
\text { that they did not believe the inflation rate } \\
\text { to be accurate they were asked 'by how } \\
\text { much do you think prices increased?' }\end{array}$} & \multicolumn{7}{|c|}{2012} \\
\hline & Average $^{1}$ & Std Deviation ${ }^{1}$ & Median $^{1}$ & Minimum & Maximum & $\%>25 \%{ }^{2}$ & $\%$ don't knows ${ }^{2}$ \\
\hline Total & 7.4 & 4.4 & 7 & 0 & 95 & 3.0 & 6.2 \\
\hline \multicolumn{8}{|l|}{ Per population group } \\
\hline $\begin{array}{l}\text { White } \\
\text { Black } \\
\text { Indian } \\
\text { Coloured }\end{array}$ & $\begin{array}{l}7.8 \\
7.0 \\
8.7 \\
7.7\end{array}$ & $\begin{array}{l}4.6 \\
4.4 \\
1.6 \\
5.2\end{array}$ & $\begin{array}{l}7 \\
7 \\
8 \\
8\end{array}$ & $\begin{array}{l}2 \\
0 \\
7 \\
2\end{array}$ & $\begin{array}{l}60 \\
95 \\
50 \\
25\end{array}$ & $\begin{array}{c}2.5 \\
2.8 \\
15.1 \\
0\end{array}$ & $\begin{array}{c}0 \\
7.4 \\
10.8 \\
11.5\end{array}$ \\
\hline \multicolumn{8}{|l|}{ Per monthly household income } \\
\hline $\begin{array}{l}\text { R8000+ } \\
\text { R4000-R7999 } \\
\text { R800-R3999 } \\
\text { R1-R799 }\end{array}$ & $\begin{array}{l}8.3 \\
8.0 \\
6.2 \\
8.8\end{array}$ & $\begin{array}{c}4.7 \\
3.8 \\
3.8 \\
10.7\end{array}$ & $\begin{array}{l}8 \\
8 \\
6 \\
2\end{array}$ & $\begin{array}{l}0 \\
0 \\
0 \\
2\end{array}$ & $\begin{array}{l}80 \\
20 \\
95 \\
82\end{array}$ & $\begin{array}{c}4.8 \\
0 \\
2.0 \\
23.5\end{array}$ & $\begin{array}{c}0 \\
9.0 \\
0.8 \\
0\end{array}$ \\
\hline \multicolumn{8}{|l|}{ Per age group } \\
\hline $\begin{array}{l}15-24 \\
25-34 \\
35-49 \\
50+\end{array}$ & $\begin{array}{l}6.9 \\
8.0 \\
7.1 \\
7.1\end{array}$ & $\begin{array}{l}4.1 \\
5.6 \\
3.6 \\
3.8\end{array}$ & $\begin{array}{l}7 \\
7 \\
7 \\
7\end{array}$ & $\begin{array}{l}0 \\
0 \\
0 \\
2\end{array}$ & $\begin{array}{l}30 \\
50 \\
95 \\
80\end{array}$ & $\begin{array}{l}1.3 \\
1.5 \\
4.3 \\
4.9\end{array}$ & $\begin{array}{l}5.2 \\
3.0 \\
6.9 \\
9.4\end{array}$ \\
\hline \multicolumn{8}{|l|}{ Per gender } \\
\hline $\begin{array}{l}\text { Male } \\
\text { Female }\end{array}$ & $\begin{array}{l}7.8 \\
7.0\end{array}$ & $\begin{array}{l}5.0 \\
4.1\end{array}$ & $\begin{array}{l}7 \\
7\end{array}$ & $\begin{array}{l}0 \\
0\end{array}$ & $\begin{array}{l}60 \\
95\end{array}$ & $\begin{array}{l}4.4 \\
2.4\end{array}$ & $\begin{array}{l}2.4 \\
7.9\end{array}$ \\
\hline \multicolumn{8}{|l|}{ Per community size } \\
\hline $\begin{array}{l}\text { Metro } \\
\text { Non-metro }\end{array}$ & $\begin{array}{l}8.8 \\
6.4 \\
\end{array}$ & $\begin{array}{l}4.2 \\
4.3\end{array}$ & $\begin{array}{c}8.5 \\
6\end{array}$ & $\begin{array}{l}0 \\
0\end{array}$ & $\begin{array}{l}95 \\
20\end{array}$ & $\begin{array}{l}6.8 \\
0.2\end{array}$ & $\begin{array}{l}3.2 \\
8.4\end{array}$ \\
\hline
\end{tabular}

${ }^{1}$ Excluding don't knows and responses exceeding 25\%; ${ }^{2}$ Percentage of responses exceeding 25\% and don't know respectively.

Sources: Ipsos, 2012 and authors' research

Table 3 represents the results from respondents asked the follow-up question to: "South Africa's official rate of inflation was 5,5 per cent in June 2012. Do you think this is a true reflection of average price increases?" Only those who responded no were then asked "what they believe price increases were". These results might have some bias, as only those individuals who did not believe that the current rate of inflation was representative of average price increases, where asked to respond. Therefore only those who view inflation as either higher or lower than the actual rate of inflation responded to this question, as those respondents who accepted the rate of inflation and those who indicated that they don't know what the rate of inflation was, were not asked the follow-up question. These responses are shown in Table 3.

A few results stand out. The first is that the averages and standard deviations are much higher than in the first subsample; and second that a very large percentage of respondents in the R1 - R799 income group reported inflation rates higher than 25 per cent (around 24 per cent of respondents). Blacks and coloureds who did not believe the inflation rate, reported rates higher than those in in the first sub-sample, while Indians in the second subsample reported a lower rate than those in the first subsample if they did not believe the inflation rate. In all other instances there were an upward bias for those who did not perceive the current inflation rate as accurate, i.e. those in the second subsample, compared to those in the first subsample.

\section{Conclusions}

This paper shows that the way in which the question on inflation perceptions is put to respondents has a bearing on the survey results. It is most encouraging that the question has been put in a way that reduces the number of "don't know" responses, thereby aligning the research findings with the findings of inflation expectations surveys. This will be the matter under consideration when the next inflation perception survey is undertaken. The research results reported in this paper confirms for the first time for South Africa evidence of a linkage between historic inflation perceptions and forwardlooking inflation expectations.

The way forward with this research is to ask the same group of respondents about their inflation perceptions and 
inflation expectations in an attempt to link the responses at the level of individual responses to confirm the evidence found in this paper. This has never been done before in South Africa, and will the first research to report on the actual linkage (or otherwise) between inflation perceptions and inflation expectations at the level of individual respondents. If this linkage can be proven, it will show evidence that one of the benefits of a policy of inflation targeting is not only anchoring inflation expectations in the current and targeted rates of inflation, but also anchoring it in perceptions of historic inflation.

\section{References}

Bank of Japan. (2013). Results of the 52nd Opinion Survey on the General Public's views and behaviour. Bank of Japan. 22 February Bureau for Economic Research. (2012). Survey of Inflation Expectations: Results report 4th Quarter 2012. Bureau for Economic Research: Stellenbosch.

Camponovo, G. (2006). Conceptual models for designing information systems supporting the strategic analysis of technology environments. Unpublished PhD thesis. University of Lausanne: Lausanne.

Easton, V. J. and McColl, J. H. ([S.a.]). Statistics Glossary. Vol 1. [Online] http://www.cas.lancs.ac.uk/glossary_v1.1/confint.html\# confinterval [Accessed on various dates].

European Commission: Economic and Financial affairs data base.

Ipsos. (2012). Survey fieldwork. Fieldwork undertaken between 8 October 2012 and 19 November 2012. Ipsos: Johannesburg

Kearney, J. M., Kearney, M. J., McElhone, S. and Gibney, M. J. (1999). Methods used to conduct pan-European Union survey on consumer attitudes to physical activity, body weight and health. Public Health Nutrition, 2(1a): 79-86.

Kershoff, G. (2000). Conducting inflation expectation surveys in South Africa. Publication of the Bureau for Economic Research: University of Stellenbosch. 24 October.

Kershoff, G. J. and Smit, B. W. (2002). Conducting inflation expectation surveys in South Africa. South African Journal for Economics, 70(3): 205-212.

Lindenmann, W. K. 2001. Research does not have to put you in the poorhouse. [Online] people.ku.edu/ dguth/Lindenmann.pdf Supplemental Result [Accessed on various dates].

Mishkin, F. S. (2004). The Economics of Money, Banking and Financial Markets. $7^{\text {th }}$ edition. Addison-Wesley Publishing Company, Inc: United States of America.

National Gambling Board. (2005). Socio-economic impact of legalised gambling in South Africa. National Gambling Board: Pretoria.

Reserve Bank of India. (2012). Inflation Expectations Survey of Households: December 2011. Reserve Bank of India. 23 January.

Reserve Bank of New Zealand. ([S.a]). J5 Household expectations survey. Reserve Bank of New Zealand.

Rossouw, J. (2006). Inflation in South Africa: 1921 to 2006. History, measurement and credibility. Unpublished PhD dissertation, University of KwaZulu-Natal.

Rossouw, J and Fourie, J. (2009). Why household surveys are not: Assessing surveys in inflation-targeting countries. International Advances in Economic Research, 15(4):485-486.

Rossouw, J Padayachee, V and Bosch, A. (2009). Links or disconnect: a first consideration of inflation expectation and inflation credibility, with specific reference to South Africa. SA Journal of Economic and Management Sciences, 12(4):475-492.

Rossouw, J Padayachee, $V$ and Bosch, A. (2011). A comparison of inflation expectations and inflation credibility in South Africa: results from survey data. South African Journal of Economic and Management Sciences, 14(3): 263-281.

Rossouw, J Padayachee, V and Fourie, J. (2008). Central bank employees and inflation credibility. Central Banking, 19(2).

Rossouw, J Padayachee, V and Joubert, F. (2010). Surveying inflation credibility: three ways. Central Banking, 20(4).

Rossouw, J Padayachee, V and Joubert, F. (2013). An international comparison of inflation credibility surveys. South African Journal of Economic and Management Sciences, 16(2): 142-153.

Samuels, L. H. (1967). Control of inflation. South African Journal of Economics, 35(4):341-360.

Statistics SA. ([S.a.]). Website. http://www.statssa.gov.za/keyindicators/CPI/CPIHistory.pdf [Accessed on various dates].

Struwig, F. W. and Stead, G. B. (2001). Planning, designing and reporting research. Pearson Education South Africa: Cape Town.

University of Melbourne. (2011). Survey of Consumer Inflation Expectations. Monthly report: March 2011. Melbourne Institute of Applied Economics and Social Research.

University of Michigan and Thomson Reuters. (2012). Survey of Consumers. Survey Research Center, Thomson Reuters/University of Michigan. 